\title{
Subject Review: Feature Extraction Based on Palm Print
}

\author{
Raniah Ali Mustafa', Amal Abdulbaqi Maryoosh'², and Zahraa Salah Dhaief ${ }^{3}$ \\ ${ }^{1-3}$ Mustansiriyah University,
}

College of Education, Department of Computer Science

Iraq

\begin{abstract}
Physiological biometrics is one of the attractive fields for researchers due to its unique and stable features. One of these physical biometrics is "Palm Print". This new approach is used in personal recognition because of the powerful information that can be extracted from the palm print. The characteristics that are extracted keeping the rules of palmprint feature extraction are very important. In spite of the huge work done in this approach, the results recorded about the palm print are still uncompleted and the techniques that used in palm print feature extraction used in recognition are still continually modified. In this paper, we present a detailed background review for many techniques and methods that are used to extract features from palm print with many various methods and procedures. A comparison between these techniques is also presented.
\end{abstract}

Key Words: Palm print, Feature Extraction, Region of interest (ROI), Euclidian distances.

\section{INTRODUCTION}

In the last decades, a variety of methods and techniques were developed trying to reach the optimality in personal recognition depending on biometrical features like iris and fingerprints. A palm print was specially used since it has a better similarity than other biometrics such as fingerprint. Palm prints is known as a scanned image for the palm area of the hand. Systems depending on Palm prints considered as a new promising research areas in recognition field. One of the most useful points of using Palm prints is the large area that could be used for extracting characteristics. Features should be extracted from a fine and oriented image so that these feature could be used successfully in recognition systems. Devices that are used in Palm prints are cheaper than those used in other biometric like iris. Palm prints images even the low resolution ones hold a variety of features like wrinkles and fine lines. Systems that could merge between fingerprint and Palm prints feature may obtain a precise results that achieve an optimal and accurate recognition of persons. Both, Palm prints and fingerprint biometrics features are expressed by a friction ridge notion. The information extracted depend on ridge structure, flow, and trait of the raised fragment of the outer skin known as epidermis[1].

The area used to extract the pervious features is usually selected from the palm image for features extraction. Palm-print characteristics had been joined in many applications with other biometric attributes for personal identification [2]. In recognition systems that uses Palm prints biometrics, benefits like low cost and reliability are gained even from low resolution scanned images. That because of the features extracted from any Palm prints like the finer points, directional, and other characteristics that are close to those obtained from fingerprint and make it more accurate and reliable. Researchers worked with palm had focused on the features extraction stage, a high rate of recognition was achieved. Although,many work were done to achieve a high degree of accuracy, the lest error matching and reasonable computing time. In this paper a comparison between many applicable methods that used in palm feature extraction was done $[3,4,5]$.

\section{LITERATURE SURVEY}

In the last few years, many methods and approaches that related to Palm prints feature extraction has been suggested. Some of these methods are discussed in the next section.

Dr. Vinayak Ashok Bharadi [6] proposed a biometric texture feature extraction technique. Their method depends on a main step of transforming a two dimensional image. Using an intermediate transformation information to generate a vector of features. The suggested technique used transformers like Walsh, DCT, and other well known methods. Results were very useful and effective for feature vector used in biometric authentication. 
M.L. Anitha and K.A. Radhakrishna Rao [7]. A novel approach is proposed to identify and determine the Region of interest (ROI) in Palm prints and inner knuckle print(IKP). The images used in this article were captured using a digital camera. They proposed a method for determining selective key points on the hand area. Using the selective key points they proposed a method for locating the ROI in the Palm prints and inner knuckleprin. The suggested method was evaluated using the database collected at the authors' institute.

I. Ahmad, Z. Jan, I. Ali Shah and J. Ahmad [8] proposed a method for extracting multiple features that can be derived from a template. They suggested a merge between hand geometry characteristics and Palm prints features to obtain accuracy and suitable level of performance. The characteristics that used in this method are hand geometry, and the length, width and ratio of palm These characteristics are combined together to produce feature vector. The proposed method extracts the features that are stabile to small changing in the location of hand. A number of features (20) are extracted from every image. A comparison of the joint characteristic vector and the stored templates yields an average joint characteristic vector. Using true positive, true negative, false positive, false negative, accuracy and runtime, the efficiency of the proposed method is calculated. The authors claim an accuracy of $95.5 \%$.

A. Nichal, S. Jadhav, K. Shikalgar and P. Maharnur [9] proposed a method for extracting features depending on texture feature extraction. When images that are used for feature extraction have a low quality, a need for a powerful extraction procedure is needed. Gabor filter (GF) is utilized to find the texture data within the Palm prints. In the proposed system, twelve filters were used one of them (number 11) was proved to be the best in accuracy. They used a combination of pre-processing and rotated preprocessed effects of images. The efficiency of the proposed method was explained through experiential results.

M. Alia , P.Yannawar and A. Gaikwad [10] suggested a method that depends on fusion of multi-algorithm to be employed in Palm prints identification. The proposed system addresses different techniques like Competitive Valley Hand Detection methods (CHVD) that applied to find the region of interest (ROI). The system was divided into three sections depending on feature extraction (FE) like (LBP), (2DLPP) and fusion of LBP+2DLPP. The authors claim that, the fusion of LBP and 2DLPP gave the best values for accuracy (98.55\%) which is better than the values obtained from applying LBP and 2DLPP separately.

A. Younesi and M. Amirani [11] proposed an identification system that depends on palm print recognition. The resilience and ease of use of Palm printss in identification systems is due to their robustness and ease of use in procedures. When ROI is extracted, it is passed through Gabor filters using variant wavelengths and orientations. An output from Gabor filters is then obtained using (BSIF). Variant BSIF values are joint and a histogram of final BSIF is finally found. The resulted features from the histogram are passed to the (KNN) classifier to obtain the identification of persons. The authors claimed to achieve a high accuracy which is better than other proposed algorithms.

A. Kareem, Z. Mohammed and J. Saud [12] Proposed an approach uses near infrared images for extracting features from Palm prints and hand vein. The biometrical features characterize a network for the dorsal venous of a hand and the palm's principle line which is used with the networks as a physiological identification system since they are unique to each individual. The entropy, energy and standard deviation are extracted.

B. Attallah, A. Serir and Y. Chahir [13] proposed a new method for multispectral palm print recognition. This method improved the performance by depending on the (LBP) filters and spiral moments features. They suggested a method for deriving a feature map using a staged procedure to create a compination of spiral and LBP characteristics by fusing both and applying the absolute minimum of redundancy On them, there are the most relevant transformers. The inter- and intra-similarities are obtained using Hamming distances. The proposed method was examined using the data obtained from the IITD, MSPolyU and PolyU PPDB databases. The authors claimed that the proposed method gave high accuracy for identification

M. KADHM, H. AYAD and M. MOHAMMED [14] proposed a method that claimed to have an accurate and reliable Palm print Recognition (PRS). They proposed methods for classification and features extraction by employing the direction, (LBP), C5.0 and (KNN). They used two dataset of palm print images (COEP) and (CASIA) to gain a recognition rate (99.7\%) and error matching rate $(0.009 \%)$.

Raniah Ali Mustafa, Haitham Salman Chyad and Rafid Aedan Haleot [15] proposed a method for recognizing Palm prints depending on a "harmony" search algorithm. They calculated the Gaussian distribution. The method has many steps, first: a 
preprocessing step in which includes a segmentation depending on the geometric shape features of the palm print. Also, cutting off (ROI) of palm prin. The ROI is then supplied as an argument to the "harmony" search algorithm, which uses minimal arguments to determine the properties of the palm print. Finally, computing distance between palm features in the ROI using Gaussian distribution. The results are used in recognizing persons depending on their Palm prints images compared with a testing set of images. The proposed method used a databases from (COEP) and (HKPU). Authors claimed that, the proposed method have effective recognition system gaining a rate of recognition $(92.60 \%)$.

X. Chen, M. Yu, F. Yue, and B. Li[16] suggested a hashing-based method(orientation field code hashing) to be used in palm print identification. They proposed a double-orientation encoding technique to reduce the unsteadiness of orientation codes, also getting a reasonable orientation codes. They also proposed a window-based characteristics calculations for fast searching. The parameters related to hashing have an influence on palm print identification. They use the database of Hong Kong PolyU largescale and the CASIA palm print. They also used a synthetic database. Authors claimed that The proposed method is approximately 1.5 times faster than current methods. They also claimed to have comparative identification accuracy.

\section{COMPARISON OF SCHEMES}

Table 1: A comparison between stated methods

\begin{tabular}{|c|c|c|c|c|c|c|}
\hline Ref. & Year & Dataset & Preprocessing & Features & $\begin{array}{l}\text { Recognition } \\
\text { rate }(\mathbf{R R}) \%\end{array}$ & Method used \\
\hline [6] & 2012 & $\begin{array}{l}\text { PolyU Palm } \\
\text { prints } \\
\text { database }\end{array}$ & $\begin{array}{l}\text { ROI Extraction for Palm } \\
\text { prints }\end{array}$ & $\begin{array}{l}\text { Walsh transform } \\
\text { along with its } \\
\text { extension to } \\
\text { Hartley, DCT, } \\
\text { Kekre Transform } \\
\text { \& Kekre } \\
\text { Wavelets. }\end{array}$ & $84.23 \%$ & $\begin{array}{l}\text { Euclidian } \\
\text { distances }\end{array}$ \\
\hline [7] & 2015 & $\begin{array}{l}\text { collected at } \\
\text { our institute }\end{array}$ & $\begin{array}{l}\text { Alignment of hand image, } \\
\text { Image thresholding, } \\
\text { Finger valley detection, } \\
\text { Finger Tip point detection } \\
\text { algorithm, Locating ROI } \\
\text { region }\end{array}$ & IKP ROI & $\begin{array}{l}\text { ERR to enhance } \\
\text { the security level } \\
\text { of biometric } \\
\text { recognition } \\
\text { systems. }\end{array}$ & $\begin{array}{l}\text { Euclidean } \\
\text { distance }\end{array}$ \\
\hline$[8]$ & 2015 & $\begin{array}{l}\text { IIT Delhi } \\
\text { Touch less } \\
\text { Palm prints }\end{array}$ & $\begin{array}{l}\text { Bounding box (palm, Palm } \\
\text { length, Palm width, Palm } \\
\text { ratio), Bounding box } \\
\text { (Hand, Hand length, } \\
\text { Finger, Finger width) }\end{array}$ & $\begin{array}{l}\text { Integrated palm } \\
\text { print \& hand } \\
\text { geometry features }\end{array}$ & $95.5 \%$ & $\begin{array}{l}\text { correlation } \\
\text { coefficient }\end{array}$ \\
\hline [9] & 2016 & DBI (DBII) & $\begin{array}{l}\text { Apply a low-pass } \\
\text { filter(LPF), Extract the } \\
\text { boundaries of the holes, } \\
\text { Compute the centre of } \\
\text { gravity ( } C x i, C y i) \text {, Line } \\
\text { up k1 and k2to get the Y- } \\
\text { axis, Extract a sub-image } \\
\text { with the fixed size on the } \\
\text { basis of coordinate system }\end{array}$ & $\begin{array}{l}\text { Gabor Function, } \\
\text { Filtering and } \\
\text { Feature Extraction }\end{array}$ & $94.5 \%$ & $\begin{array}{l}\text { a normalized } \\
\text { hamming } \\
\text { distance }\end{array}$ \\
\hline$[10]$ & 2017 & CASIA & $\begin{array}{l}\text { Competitive Valley Hand } \\
\text { Detection methods } \\
\text { (CHVD), extract Region } \\
\text { of Interest (ROI) }\end{array}$ & $\begin{array}{c}\text { Local Binary } \\
\text { Pattern (LBP), } \\
\text { Two-Dimensional } \\
\text { Locality } \\
\text { Preserving } \\
\text { Projection } \\
\text { (2DLPP) and } \\
\text { fusion of }\end{array}$ & $98.55 \%$ & $\begin{array}{l}\text { Euclidean } \\
\text { distance }\end{array}$ \\
\hline
\end{tabular}


International Journal of Engineering Research and Advanced Technology, Vol. 7, No.8, August -2021

\begin{tabular}{|c|c|c|c|c|c|c|}
\hline & & & & LBP+2DLPP & & \\
\hline [11] & 2017 & $\begin{array}{l}\text { PolyU } \\
\text { database }\end{array}$ & $\begin{array}{l}\text { Extract ROI, Pass ROI } \\
\text { through Gabor filters, } \\
\text { Compute BSIF of outputs } \\
\text { of filtered Palm printss }\end{array}$ & $\begin{array}{l}\text { histogram features } \\
\text { of final BSIF code }\end{array}$ & $99.27 \%$ & KNN classifier \\
\hline [12] & 2019 & IIT Delhi & $\begin{array}{c}\text { enhancement filters } \\
\text { (Gaussian filter), gray scale } \\
\text { image, edge } \\
\text { detection algorithm, } \\
\text { Marking gaps between } \\
\text { index and middle fingers, } \\
\text { and between little and ring } \\
\text { fingers, ROI extracted }\end{array}$ & $\begin{array}{l}\text { statistical feature } \\
\text { (mean ,standard } \\
\text { deviation, energy, } \\
\text { entropy ) }\end{array}$ & - & - \\
\hline [13] & 2019 & $\begin{array}{c}\text { IITD, } \\
\text { MSPolyU } \\
\text { and PolyU } \\
\text { PPDB }\end{array}$ & $\begin{array}{c}\text { Extract region of } \\
\text { interest }(\mathrm{ROI})\end{array}$ & $\begin{array}{c}\text { Spiral of } \\
\text { statistical local } \\
\text { features (SSLF), } \\
\text { LBP features, } \\
\text { Features sélection } \\
\text { (mRMR) }\end{array}$ & $\begin{array}{l}\text { achieved high } \\
\text { levels of } \\
\text { accuracy }\end{array}$ & $\begin{array}{c}\mathrm{k}^{-N^{-}} \operatorname{arest}^{-} \\
\text {neighbor }(\mathrm{KNN})\end{array}$ \\
\hline [14] & 2021 & $\begin{array}{l}\text { College of } \\
\text { Engineering } \\
\text { Pune } \\
\text { (COEP), } \\
\text { Chinese } \\
\text { Academy of } \\
\text { Sciences } \\
\text { (CASIA) }\end{array}$ & $\begin{array}{c}\text { Remove the image } \\
\text { background, } \\
\text { Apply Gaussian filter (GF), } \\
\text { Convert image into binary, } \\
\text { Detect the image edges } \\
\text { using Canny filter (CF), } \\
\text { Extract region of } \\
\text { interest (ROI) }\end{array}$ & $\begin{array}{l}\text { Local Binary } \\
\text { Pattern (LBP) }\end{array}$ & $99.7 \%$ & $\begin{array}{l}\text { Decision Tree } \\
\text { (DT) and K- } \\
\text { Nearest } \\
\text { Neighbour } \\
\text { (KNN) }\end{array}$ \\
\hline [15] & 2021 & $\begin{array}{l}\text { college of } \\
\text { engineering } \\
\text { pune } \\
(\mathrm{COEP})\end{array}$ & $\begin{array}{l}\text { segmentation, region of } \\
\text { interest (ROI), and edge } \\
\text { detector }\end{array}$ & $\begin{array}{l}\text { Harmony search } \\
\text { algorithm (HAS) }\end{array}$ & $92.60 \%$. & $\begin{array}{c}\text { Gaussian } \\
\text { distribution }\end{array}$ \\
\hline [16] & 2021 & $\begin{array}{l}\text { Hong Kong } \\
\text { PolyU and } \\
\text { CASIA plus } \\
\text { a synthetic } \\
\text { database }\end{array}$ & $\begin{array}{l}\text { POP hashing and A-POP } \\
\text { hashing }\end{array}$ & $\begin{array}{l}\text { Orientation field- } \\
\text { based methods, a } \\
\text { window-based } \\
\text { feature } \\
\text { measurement }\end{array}$ & $98.88 \%$ & $\begin{array}{l}\text { hashing-based } \\
\text { methods }\end{array}$ \\
\hline
\end{tabular}

\section{CONCLUSION}

In this review, we tried to explain the major work of various methods used in feature extraction based on Palm prints during the period (2012-2021). Palm print recognition systems and identification systems in which biometrical techniques are considered new and promising. Palm printss (palm's features) containing many similarity characteristics that used in distinguishing between persons to precise individual recognition. This study uses palm print images for focusing on extract features. Those schemes of recognition are thoroughly investigated and analyzed in order to improve the recognition and identification efficiency through extract features best for region of interest(ROI) and to ensure Efficiency performance. According to the findings of this work, all of these approaches are useful for extract features. Every plan is unique in its approach, which might be suitable for a variety of purposes. Today, new technology of recognition is being developed on a daily basis, and recently, suggested extract feature based on palm print images technologies have also increased security. Every technology has a set of advantages and disadvantages; thus, new technologies have become more advanced. 


\section{ACKNOWLEDGMENT}

The authors would like to thank Mustansiriyah University (https://uomustansiriyah.edu.iq, Baghdad- Iraq) for its support in this work.

\section{REFERENCES}

1. Kanchana .A and Stanly Jayaprakash .J, "INTRODUCTION TO PALM PRINTS RECOGNITION", International Research Journal of Engineering and Technology (IRJET), e-ISSN: 2395-0056, p-ISSN: 23950072, Volume: 04 Issue: 11 | Nov -2017.

2. S.Adebayo Daramola, Olujimi Ajayi and Tiwalade Odu, "Robust Palm-Print Feature for Human Identification", International Journal of Engineering and Advanced Technology (IJEAT), ISSN: 2249 - 8958, Volume-3, Issue-4, April 2014.

3. MUSTAFA S. KADHM, HAYDER AYAD and MAMOUN JASSIM MOHAMMED, " PALM PRINTS RECOGNITION SYSTEM BASED ON PROPOSED FEATURES EXTRACTION AND (C5.0) DECISION TREE, KNEAREST NEIGHBOUR (KNN ) CLASSIFICATION APPROACHES", Journal of Engineering Science and Technology, Vol. 16, No. 1 (2021) 816 - 831.

4. Dimitrios Marmanis, Mihai Datcu, Thomas Esch and Uwe Stilla, "Deep Learning Earth Observation Classification Using ImageNet Pretrained Networks", IEEE GEOSCIENCE AND REMOTE SENSING LETTERS, VOL. 13, NO. 1, JANUARY 2016.

5. Sun, Q., Zhang, J., Yang, A., and Zhang, Q.,"Palm prints recognition with deep convolutional features. Chinese Conference on Image and Graphics Technologies", Springer, Singapore, 12-19, 2017.

6. Dr. Vinayak Ashok Bharadi," Texture Feature Extraction For Biometric Authentication using Partitioned Complex Planes in Transform Domain", IJACSA Special Issue on Selected Papers from International Conference \& Workshop On Emerging Trends In Technology 2012.

7. M.L. Anitha and K.A. Radhakrishna Rao, "Extraction of Region of Interest (ROI) for Palm Print and Inner Knuckle Print”, International Journal of Computer Applications (0975 - 8887), Volume 124 - No.14, August 2015.

8. Irfan Ahmad, Zahoor Jan, Inayat Ali Shah and Jamil Ahmad, "HAND RECOGNITION USING PALM AND HAND GEOMETRY FEATURES”, Sci.Int.(Lahore),27(2),1177-1181, ISSN 1013-5316; CODEN: SINTE $8,2015$.

9. Prof. Arjun Nichal, Ms. Supriya Jadhav, Ms. Karishma Shikalgar and Ms. Poonam Maharnur, "Palm Print Feature Extraction and Authentication Using 2-D Gabor Filter", International Journal of Advanced Research in Computer and Communication Engineering, ISSN (Online) 2278-1021, ISSN (Print) 23195940 ,Vol. 5, Issue 4, April 2016.

10. Mouad M.H.Alia, Pravin L.Yannawar and A. T. Gaikwad, "Multi-Algorithm of Palm prints Recognition System Based on Fusion of Local Binary Pattern and Two-Dimensional Locality Preserving Projection", 7th International Conference on Advances in Computing \& Communications, ICACC-2017, 22- 24 August 2017, Cochin, India.

11. Ali Younesi and Mehdi Chehel Amirani," Gabor Filter and Texture based Features for palm print Recognition", International Conference on Computational Science, ICCS 2017, 12-14 June 2017, Zurich, Switzerland.

12. Abdul Kareem,Z. Mohammed and Jamila H. Saud," Feature Extraction from hand Dorsal Vein and Palm prints", International Journal of Advanced Research in Computer Engineering \& Technology (IJARCET),ISSN: 2278 - 1323, Volume 08, Issue 03, March 2019.

13. Bilal Attallah, Amina Serir and Youssef Chahir," Feature extraction in Palm prints recognition using spiral of moment skewness and kurtosis algorithm", Pattern Analysis and Applications, Springer Verlag, 22 (3), pp.1197-1205, 2019.

14. Mustafa S. Kadhm, Hayder Ayad And Mamoun Jassim Mohammed,"Palm Prints Recognition System Based On Proposed Features Extraction And (C5.0) Decision Tree, K-Nearest Neighbour (Knn ) Classification Approaches", Journal Of Engineering Science And Technology Vol. 16, No. 1 (2021) 816 - 831.

15. Raniah Ali Mustafa, Haitham Salman Chyad and Rafid Aedan Haleot," Palm print recognition based on harmony search algorithm", International Journal of Electrical and Computer Engineering (IJECE), ISSN: 2088-8708, DOI: 10.11591/ijece.v11i5.pp4113-4124,Vol. 11, No. 5, October 2021, pp. 4113 4124.

16. Xi Chen, Ming Yu, Feng Yue, and Bin Li," Orientation Field Code Hashing:A Novel Method for Fast Palm prints Identification",IEEE/CAA JOURNAL OF AUTOMATICA SINICA, Digital Object Identifier 10.1109/JAS.2020.1003186,VOL. 8, NO. 5, MAY 2021.

${ }^{1}$ C. Author: rania83computer@uomustansiriyah.edu.iq 